\title{
Research on Simulink/Fluent Collaborative Simulation Zooming of Marine Gas Turbine
}

\author{
Zhi-tao Wang, Jian Li, Tie-lei Li, and Shu-ying Li \\ College of Power and Energy Engineering, Harbin Engineering University, Harbin 150001, China \\ Correspondence should be addressed to Tie-lei Li; ltl_heu@163.com
}

Received 30 September 2016; Accepted 15 December 2016; Published 2 March 2017

Academic Editor: Wu Deng

Copyright (C) 2017 Zhi-tao Wang et al. This is an open access article distributed under the Creative Commons Attribution License, which permits unrestricted use, distribution, and reproduction in any medium, provided the original work is properly cited.

Based on the detailed analysis of collaborative running interface of Simulink/Fluent, a system simulation for the rated working condition as well as variable working condition of marine gas turbine has been achieved, which can improve the simulation efficiency of marine gas turbine by developing simulation model of combustor with Fluent and simulation models of other components with Simulink. The result shows that the Simulink/Fluent collaborative simulation zooming can make the inner working conditions of combustor be observed specifically, based on the overall performance matching analysis; thus an effective technical means for the structural optimization design of combustor has been provided.

\section{Introduction}

System simulation technology is an effective means for marine gas turbine modular design, and simulation models with different dimension are selected for different components according to the need of research in the process of simulation to achieve the simulation zooming, so that a reasonable balance can be found between the degree of model's fineness and time-consuming of simulation, thus to improve the simulation efficiency. For example, during the overall scheme design, conducting system simulation just with $0 \mathrm{D}$ component models can basically meet the need of the overall performance matching analysis; when designing the structural optimization for a component, what is needed to do is just the distribution parameter calculation to the component, while the other components can still select $0 \mathrm{D}$ model. Thus detailed research for the inner mechanism to the component can be performed on the basis of overall performance matching.

In the process of modular modeling, one can make full use of various types of commercial simulation software which have different characteristics. Usually, each kind of commercial simulation software belongs to a specific science field and supports the simulation model of specific dimension. For example, Matlab/Simulink is accomplished in dynamic system modeling and simulation, which can be used to establish the gas turbine control system or the 0D simulation model of other components appropriately; Fluent specializes in analyzing fluid field and temperature field, which is suitable to establish $2 \mathrm{D}$ or 3D dimensional steady state simulation model of combustor. Using the collaborative running interface of Simulink/Fluent, the simulation models established by two kinds of simulation software are coupled together to achieve the simulation zooming, which has been applied in simulation research of many science fields [1-5].

In order to expand the application field and enhance the versatility, Fluent provides the following interface for users [1]: Fluent/UDF is written based on C language to deal with the nonfixed boundary conditions or dynamic grid computing and other personalized applications; Fluent/Journal is used to record the operation sequence on the Fluent/GUI and then Fluent can be started by the external program including command with Journal parameter, so that simulation task is automatically operated according to the operation sequence in Journal. The simulation results at calculation regional boundary can be stored in specified text file by Fluent to facilitate sharing data with external program.

$\mathrm{S}$-Function is the computer language description of the Simulink simulation module and it also provides a variety of language version templates which can be used to customize the simulation module by researchers. S-Function is composed of a number of callback functions. Figure 1 shows the 


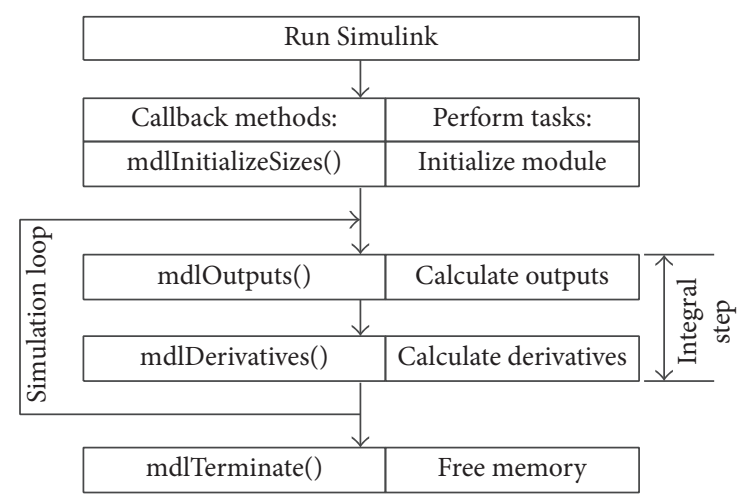

Figure 1: Invocation mode of Simulink/S-Function.

invocation mode for the main callback functions (M language version) by the Simulink solver at different simulation stages of fixed step algorithm [6]. At the initialization stage of the simulation, Simulink solver calls the callback function "mdlInitializeSizes()" to determine simulation module state quantity, initial state value, sampling time, and other basic information; at each integral step of simulation loop stage, Simulink solver calls the callback function "mdlOutputs()" to calculate output data value of the simulation module; if there is a continuous state in the simulation module, the Simulink solver needs to call the callback function "mdlDerivatives()" to achieve integral for the continuous state; at the end of the simulation, Simulink solver calls the callback function "mdlTerminate()" to release the storage space. It should be noted that the Simulink solver will call the corresponding callback function of all the simulation modules in sequence. For example, at each integral step of simulation loop stage, Simulink solver will call the callback function "mdlOutputs()" of all the simulation modules in sequence and then call "mdlDerivatives()" function of all the simulation modules.

Making use of external interface of Fluent and Simulink, the following three approaches can achieve Simulink/Fluent collaborative simulation: Fluent is embedded in Simulink [4, 5]; that is, Fluent simulation model is encapsulated to a simulation module which has the same attribute and operation style with the build-in module and participates in the running of the Simulink simulation model; Simulink is embedded in Fluent [1]; that is, Simulink simulation model is compiled into C function for Fluent/UDF to call; Simulink and Fluent run parallelly that is to achieve simulation collaboration through the global variate [1] or a kind of process blocking technology $[2,3]$. As the first approach has more advantages in versatility and flexibility, it has become the mainstream of current application.

The general idea to develop the collaborative running interface of Simulink/Fluent, based on the first approach, is as follows $[4,5]$ : develop interface program based on Simulink/ S-Function; start Fluent with command including Journal parameter; store the update values of the S-Function input ports into a text file; access the text file by Fluent/UDF and using these values to deal with nonfixed boundary conditions; at last, Fluent will store the simulation results of the calculation regional boundary into another text file and S-Function will access this text file to propagate its values to Simulink via output ports. Because many boundary conditions and physical parameters in Fluent simulation model cannot be modified by UDF, the interface developed by the idea mentioned above cannot be applied in some specific fields.

In Methodology, a new collaborative running interface of Simulink/Fluent is developed, which is also inside the range of the first approach. Compared with the existing one, the new collaborative running interface provides boundary conditions for Fluent environment by modifying parameters of Journal directly, instead of tedious UDF programming.

In Application, the simulation zooming research is conducted that takes triaxial gas turbine of a certain type as physical model, establishing 2D simulation model for the combustor with Fluent, establishing system simulation model which consists of $0 D$ component simulation models with Simulink. The 2D simulation model of combustor is embedded in the Simulink environment by encapsulating the written collaborative running interface of Simulink/Fluent to S-Function module.

\section{Methodology}

2.1. Collaborative Running Interface of Simulink/Fluent. Fluent/Journal and Simulink/S-Function have the following features: Journal uses standard syntax format to record operation sequence; Fluent is able to read the Journal which is saved as text format; S-Function can call the powerful M functions to read, write, and modify the text file. Considering these features, it can be used to modify the parameters in the Journal text file directly to deal with the nonfixed boundary condition, which can avoid the tedious UDF programming. Based on the idea above, this paper developed the Simulink/ Fluent collaborative running interface of a certain type triaxial gas turbine simulation zooming, using the $M$ language version template of S-Function. Figure 2 shows the workflow of Simulink/Fluent collaborative running interface. The dotted line 1 in Figure 2 denotes that the Simulink solver always starts Fluent with command including Journal parameter at each integral step. The dotted line 2 in Figure 2 denotes that, according to the current simulation time, the simulation results (Cas and Dat document) generated by Fluent are renamed by the Simulink solver at each integral step to avoid the automatic coverage of the Fluent simulation results. For example, when the current simulation time is $1 \mathrm{~s}$, the simulation results are renamed " 1 s.cas" and " 1 s.dat"; when the current simulation time is $1.05 \mathrm{~s}$, the simulation results are renamed " 1.05 s.cas" and "1.05 s.dat."

\subsection{Mathematical Model of Marine Gas Turbine}

2.2.1. Combustor. While the combustion process of liquid fuel in the combustor is simulated by distributed parameter, assumptions are typically made as follows [7]: chemical reaction occurs with the liquid fuel in gas-phase; the inner and surface of fuel droplet only change physically, and the carrier mobility of droplet is less than 5\%; the process of turbulent 

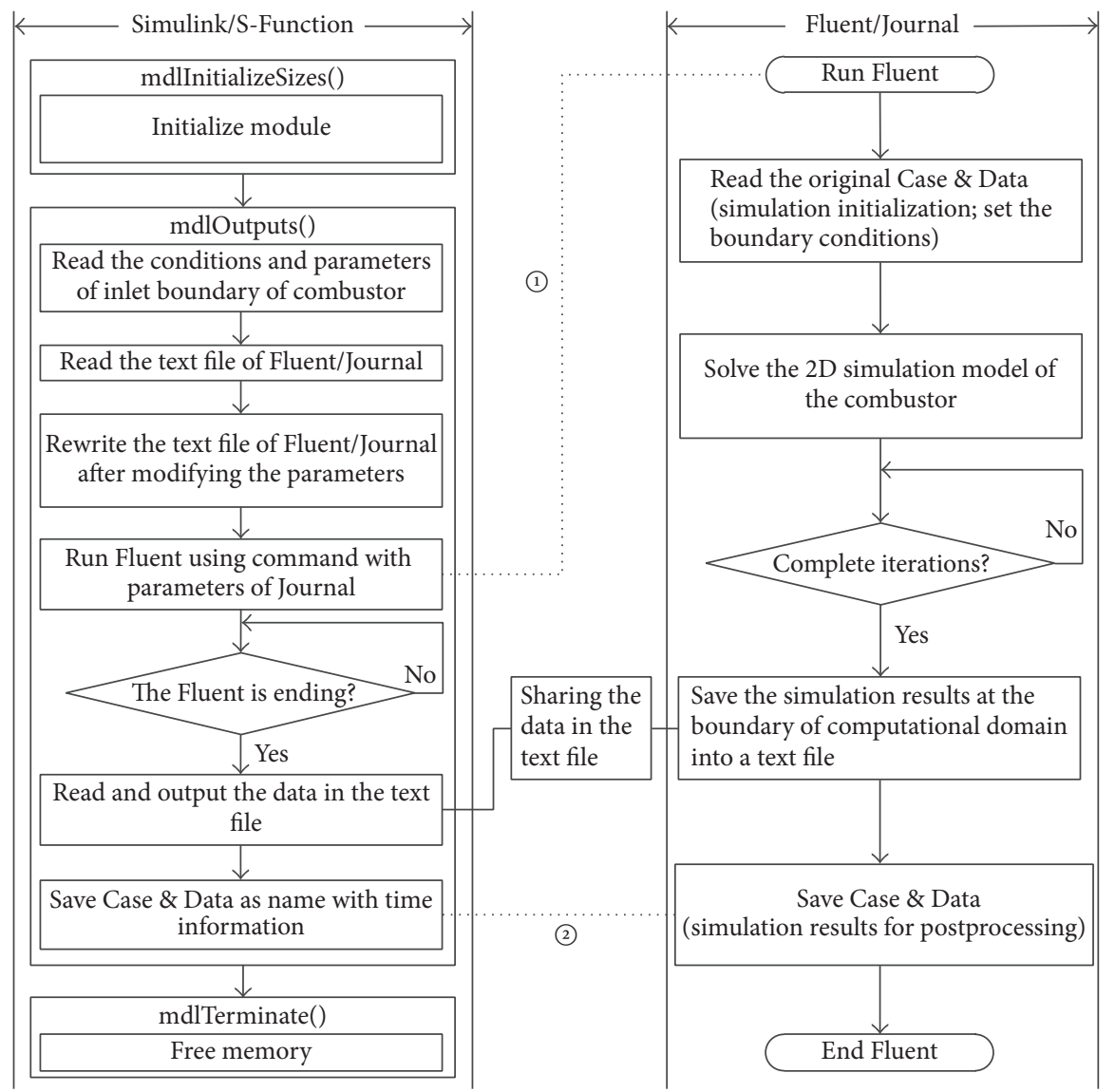

FIGURE 2: Workflow of Simulink/Fluent collaborative running interface.

diffusion combustion of liquid fuel can be treated as the liquid-phase particles motion of Lagrange coordinates along their orbits and gas-phase turbulent flow and chemical reaction process of Euler coordinates, the two processes coupled to each other to achieve the continuous heat and mass transfer between discrete-phase and continuous-phases; the heat and mass transfer in the combustion process of gaseous fuel only occurs in the continuous-phases; the combustion flow field is in the states of thermodynamic equilibrium and chemical equilibrium. On the basis of these assumptions, the mathematical model of distribution parameter of combustor is established, including gas-phase basic control equation [810], RNG $k-\varepsilon$ turbulence model [11], EDC combustion model [12-15], and control equations of discrete-phase [16-18].

2.2.2. The Other Components. This paper takes triaxial gas turbine of a certain type as physical model (as it is shown in Figure 3). The main mathematical model established according to the traditional method of volume inertia is as follows:

$$
\begin{gathered}
\frac{d n_{\mathrm{LT}}}{d t}=\frac{900}{J_{\mathrm{LT}} \pi^{2} n_{\mathrm{LT}}}\left\{G_{\mathrm{LT}} C_{p g} T_{5}[1\right. \\
\left.-\left(1-\frac{1}{e_{\mathrm{LT}}^{\left(k_{g}-1\right) / k_{g}}}\right) \eta_{\mathrm{LT}}\right]
\end{gathered}
$$

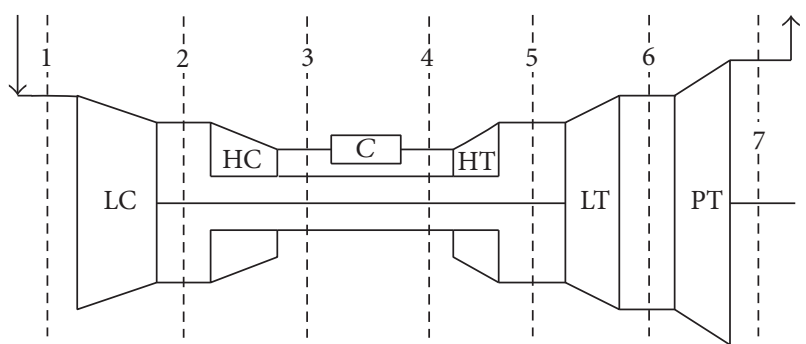

Figure 3: Physical model of triaxial gas turbine.

$$
\begin{array}{r}
\left.-\frac{G_{\mathrm{LC}} C_{p a} T_{1}\left(\beta_{\mathrm{LC}}\left(k_{a}-1\right) / k_{a}-1\right)}{\eta_{\mathrm{LC}}}\right\} \\
\frac{d n_{\mathrm{HT}}}{d t}=\frac{900}{J_{\mathrm{HT}} \pi^{2} n_{\mathrm{HT}}}\left\{G_{\mathrm{HT}} C_{p g} T_{4}[1\right. \\
\left.-\left(1-\frac{1}{e_{\mathrm{HT}}\left(k_{g}-1\right) / k_{g}}\right) \eta_{\mathrm{HT}}\right] \\
\left.-\frac{G_{\mathrm{HC}} C_{p a} T_{2}\left(\beta_{\mathrm{HC}}\left(k_{a}-1\right) / k_{a}-1\right)}{\eta_{\mathrm{HC}}}\right\}
\end{array}
$$


TABLE 1: Main performance parameters of triaxial gas turbine of a certain type.

\begin{tabular}{lc}
\hline Performance parameters & Design values \\
\hline$T_{2}(\mathrm{~K})$ & 486.1 \\
$T_{3}(\mathrm{~K})$ & 769.9 \\
$T_{4}(\mathrm{~K})$ & 1542.8 \\
$T_{5}(\mathrm{~K})$ & 1241 \\
$T_{6}(\mathrm{~K})$ & 1056.2 \\
$G_{a}(\mathrm{~kg} / \mathrm{s})$ & 82.1 \\
$G_{f}(\mathrm{~kg} / \mathrm{s})$ & 1.62 \\
$n_{\mathrm{HT}}(\mathrm{rpm})$ & 9740 \\
$n_{\mathrm{LT}}(\mathrm{rpm})$ & 7436 \\
$n_{\mathrm{PT}}(\mathrm{rpm})$ & 3270 \\
$\eta_{\mathrm{GT}}$ & $34.94 \%$ \\
$N_{\mathrm{GT}}(\mathrm{kw})$ & 24265 \\
\hline
\end{tabular}

$$
\begin{aligned}
& \frac{d n_{\mathrm{PT}}}{d t}=\frac{900}{J_{\mathrm{PT}} \pi^{2} n_{\mathrm{PT}}}\left(N_{\mathrm{PT}}-L\right) \\
& G_{f}=f\left(n_{\mathrm{PT}}\right) \\
& \frac{d p_{2}}{d t}=\frac{R_{a} T_{2}}{V_{\mathrm{LC} \sim \mathrm{HC}}}\left(G_{\mathrm{LC}}-G_{\mathrm{HC}}\right) \\
& \frac{d p_{3}}{d t}=\frac{R_{a} T_{3}}{V_{\mathrm{C}}}\left(G_{b \mathrm{in}}+G_{f}-G_{b o u t}\right) \\
& T_{3}=f\left(h_{3}\right) \\
& \frac{d p_{5}}{d t}=\frac{R_{g} T_{5}}{V_{\mathrm{HT} \sim \mathrm{LT}}}\left(G_{\mathrm{HT}}-G_{\mathrm{LT}}\right) \\
& \frac{d p_{6}}{d t}=\frac{R_{g} T_{6}}{V_{\mathrm{LT} \sim \mathrm{PT}}}\left(G_{\mathrm{LT}}-G_{\mathrm{PT}}\right),
\end{aligned}
$$

where $V_{\mathrm{LC} \sim \mathrm{HC}}$ is the volume between low-pressure compressor and high-pressure compressor; subscript $a$, subscript $g$, and subscript $f$ are air, gas, and fuel; and subscript $b$ in and subscript bout are inlet and outlet of combustor; refer to Figure 3 for the meaning of other subscripts.

Make use of $G_{f}, G_{b \text { in }}, p_{3}$, and $T_{3}$, the distributed parameter model of combustor outputs $p_{4}$ and $T_{4}$, which are processed with average method at the output boundary of combustor.

\section{Application}

3.1. Simulation Model of Marine Gas Turbine. The triaxial gas turbine of a certain type is mainly used in mechanical or electric propulsion of marine, whose main performance parameters are shown in Table 1 , where $\eta_{\mathrm{GT}}$ and $N_{\mathrm{GT}}$ are efficiency and output power of marine gas turbine; refer to Figure 3 for the meaning of other subscripts.

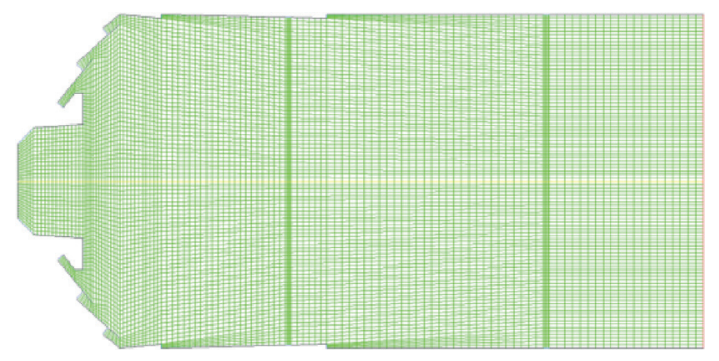

FIGURE 4: Grid structure for 2D simulation model of combustor.

3.1.1. Combustor. The Fluent environment is selected to develop the simulation model of distributed parameter of combustor; the specific process is shown in Figure 4.

Discretization of Computational Domain. Taking the 3D solid model of loop-type flame tube of combustor of a certain type triaxial gas turbine as reference, a $2 \mathrm{D}$ axisymmetric model is built by the way of area average, and the discrete computational domain is also built on the basis of structured grid. As it is shown in Figure 4, the 2D model maintains the proper swirl holes, primary holes, mixing holes, head, and cooling holes, the corresponding domain of grid is properly encrypted, and the total number of grids is 5355 .

Adding Mathematical Models and Boundary Conditions. The mathematical models described previously are sequentially added to the simulation model (e.g., RNG $k$ - $\varepsilon$ turbulence model). Considering the working condition of combustor and the algorithm condition used in calculation, the following boundary conditions are added to the simulation model [7]: the inlet of air, including mass flow, temperature, turbulence intensity, hydraulic diameter, and average mixing fraction; the inlet of fuel, including fuel type (using liquid fuel $\mathrm{C}_{7} \mathrm{H}_{16}$ ), injection mode and swirl angle of pressure swirl atomizer, mass flow, and temperature; the outlet of gas, including reflux temperature, turbulence intensity, and hydraulic diameter; making sure the wall is the heat insulating wall and has no slip velocity, whose parameters are zero, including turbulence parameter, concentration, and normal gradient of square value of concentration pulsation.

Solver Settings. The solver of Fluent automatically makes the convection term, diffusion term, and source term of basic control equation be discrete based on the structured grid of computational domain. This paper selects Simple algorithm [10] to solve the discrete simulation model, which uses "guess-correction" process, computing pressure-velocity coupling field by use of staggered grid; the number of iterations is 400 .

3.1.2. System Simulation Model of Marine Gas Turbine. The Simulink environment is selected to develop the system simulation model which consists of $0 \mathrm{D}$ component simulation models $[19,20]$. The $2 \mathrm{D}$ simulation model of combustor is embedded in the Simulink environment by encapsulating the written collaborative running interface of Simulink/Fluent to S-Function module which is named fluent_sub, to carry 


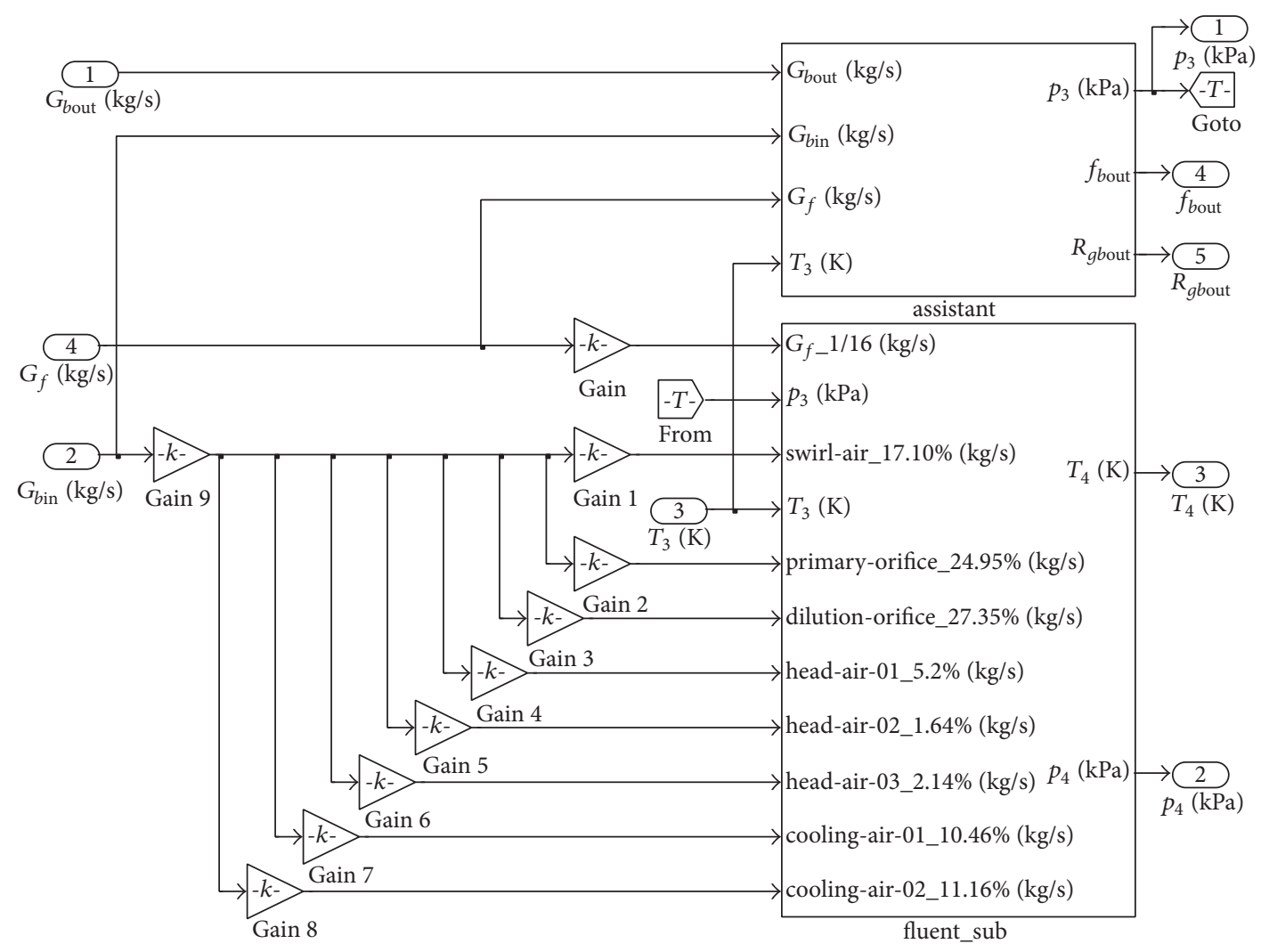

FIGURE 5: 2D simulation model of combustor developed in Simulink environment.

out the simulation zooming. As it is shown in Figure 5, the assistant module on one hand plays a role of volume module, to provide combustor inlet pressure $p_{3}$ for Fluent simulation model; on the other hand, it outputs the air-fuel ratio $f_{\text {bout }}$ and gas constant of combustor outlet $R_{\text {gbout }}$, which cannot be outputted by Fluent simulation model.

Figure 1 shows the solving process of system simulation model; all the differential equations established according to the method of volume inertia are calculated in the callback method "mdlDerivatives()," which achieves integral.

\subsubsection{Result Analysis}

Verification of the Simulation Results on Rated Working Condition. Simulation experimental scheme is shown in Table 2, the setting value of speed of gas turbine controller is $3270 \mathrm{rpm}$, load power is $24265 \mathrm{kw}$, and integral step is $0.05 \mathrm{~s}$. As shown in Table 2, comparing with the design values of rated working condition [21], the errors of simulation zooming are less than $5 \%$, this preliminarily verifies the feasibility of simulation zooming research. The simulation errors of the amount of fuel and work efficiency are relatively large; the reason is the following: considering the limited computing capability of model runtime environment, in order to reduce the timeconsuming of simulation, this paper simplifies the 3D simulation model of combustor to the $2 \mathrm{D}$ one, so that the air goes evenly into the flame tube through the primary holes, mixing holes, cooling holes, and so on; in the $3 \mathrm{D}$ model, several small holes are arranged around aforementioned holes in the circumferential direction, the air goes into the flame tube through the small holes, this difference weakens the intensity of the air injection so that the penetration depth and its influence on the combustion flow field are not as apparent as $3 \mathrm{D}$ model, and the central recirculation zone formed by which is not big enough, causing incomplete combustion of some fuel, brings about relatively large simulation errors of the amount of fuel and work efficiency; the collaborative running interface of Simulink/Fluent has the versatility, if we can upgrade the runtime environment; selecting $3 \mathrm{D}$ simulation model of combustor to participate in simulation zooming, simulation accuracy will be improved.

Analysis of Simulation Results on Variable Working Condition. Simulation experimental scheme is shown in Table 2; the setting value of speed of gas turbine controller is $3000 \mathrm{rpm}$, total simulation time is $95 \mathrm{~s}$, integral step is $0.05 \mathrm{~s}$, load power is $24265 \mathrm{kw}$ at $0 \mathrm{~s}, 30 \%$ load power is suddenly decreased at $5 \mathrm{~s}, 30 \%$ load power is suddenly decreased at $35 \mathrm{~s}$ again, and $20 \%$ load power is suddenly decreased at 65 s finally. As it is shown from Figures 6-9, the speed of power turbine suddenly increases when the load power is suddenly decreased, under the function of gas turbine controller, the fuel flow is rapidly decreased, leading to the initial temperature of combustor inlet, output power and speed of power turbine will change at the same trend. From the sudden load decrease to the corresponding steady state of gas turbine, the adjustment time 
TABLE 2: Verification of simulation results on rated working condition.

\begin{tabular}{lccc}
\hline $\begin{array}{l}\text { Simulation } \\
\text { data }\end{array}$ & Design values & $\begin{array}{c}\text { Simulation } \\
\text { zooming values }\end{array}$ & $\begin{array}{c}\text { Simulation } \\
\text { errors }\end{array}$ \\
\hline$T_{2}(\mathrm{~K})$ & 486.1 & 484.2 & $0.391 \%$ \\
$T_{3}(\mathrm{~K})$ & 769.9 & 767 & $0.377 \%$ \\
$T_{4}(\mathrm{~K})$ & 1542.8 & 1563 & $1.309 \%$ \\
$T_{5}(\mathrm{~K})$ & 1241 & 1239 & $0.161 \%$ \\
$T_{6}(\mathrm{~K})$ & 1056.2 & 1065 & $0.833 \%$ \\
$G_{a}(\mathrm{~kg} / \mathrm{s})$ & 82.1 & 83.4 & $1.583 \%$ \\
$G_{f}(\mathrm{~kg} / \mathrm{s})$ & 1.62 & 1.689 & $4.259 \%$ \\
$n_{\mathrm{HT}}(\mathrm{rpm})$ & 9740 & 9887 & $1.509 \%$ \\
$n_{\mathrm{LT}}(\mathrm{rpm})$ & 7436 & 7495 & $0.793 \%$ \\
$\eta_{\mathrm{GT}}$ & $34.94 \%$ & $34.03 \%$ & $2.604 \%$ \\
\hline
\end{tabular}

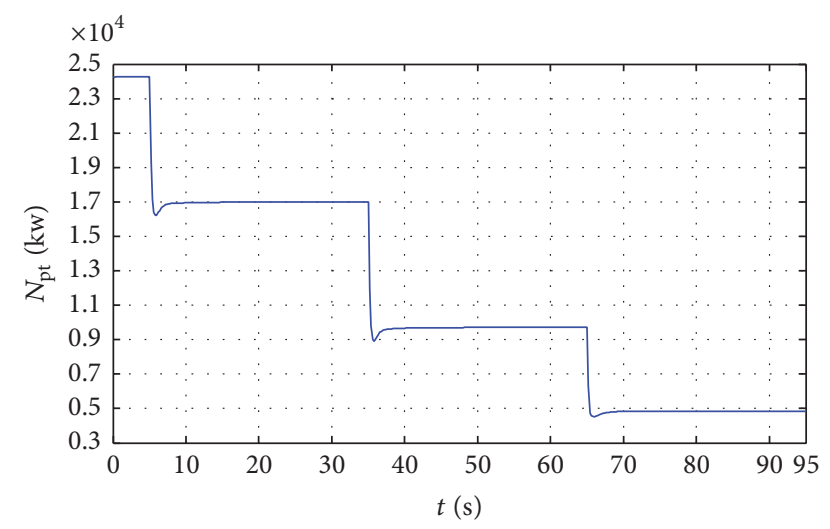

FIGURE 6: Simulation result of output power.

is about $10 \mathrm{~s}$. The above simulation results are conforming to reality, it proves the feasibility of simulation zooming research once again.

The simulation zooming can conduct partially "zoom in" for a component on the basis of the overall performance matching analysis, so the inner working conditions can be observed in detail. Seen from the invocation mode of Simulink/S-Function and the workflow of Simulink/Fluent collaborative running interface described previously, the simulation results of distributed parameter of combustor can be obtained through the simulation zooming research, at each integral step, so we can analysis the inner working conditions of combustor on any working condition. For example, according to the system simulation results on variable working condition, the inner working conditions of combustor on $20 \%$ working condition can be clearly analyzed by the simulation results of distributed parameter at corresponding simulation time.

Figure 10 shows the inner temperature distribution of combustor, the temperature range is about $465 \mathrm{~K}-2700 \mathrm{~K}$, high-temperature zone is concentrated in center front of combustion flow field and both sides of central recirculation zone, under the joint action of primary air and mixing air, and it is convergent along the axial trend of combustor, forming the more uniform mixing gas at the outlet. The maximum

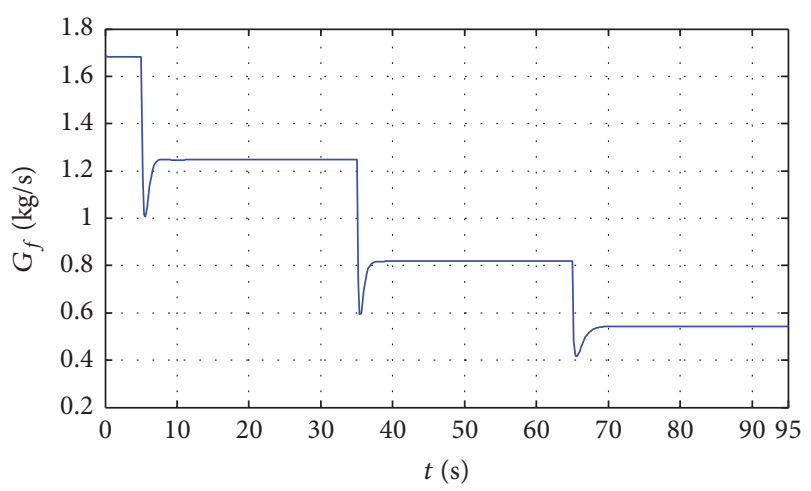

FIgURE 7: Simulation result of fuel flow.

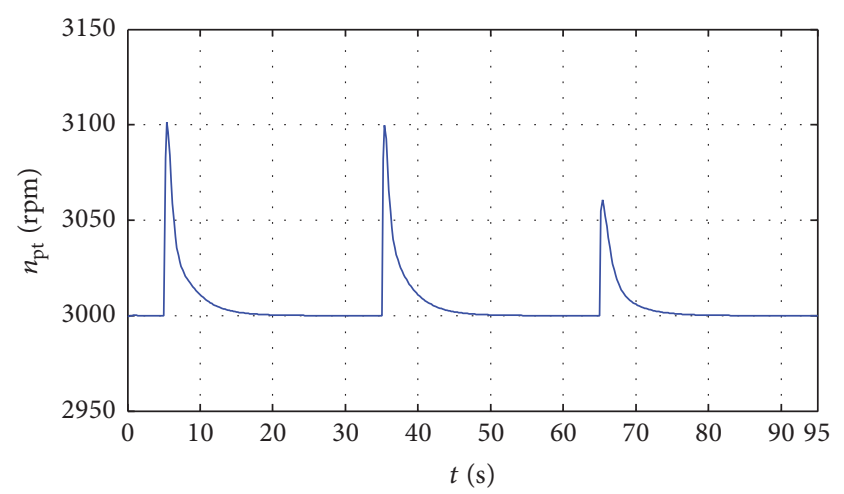

FIGURE 8: Simulation result of speed of power turbine.

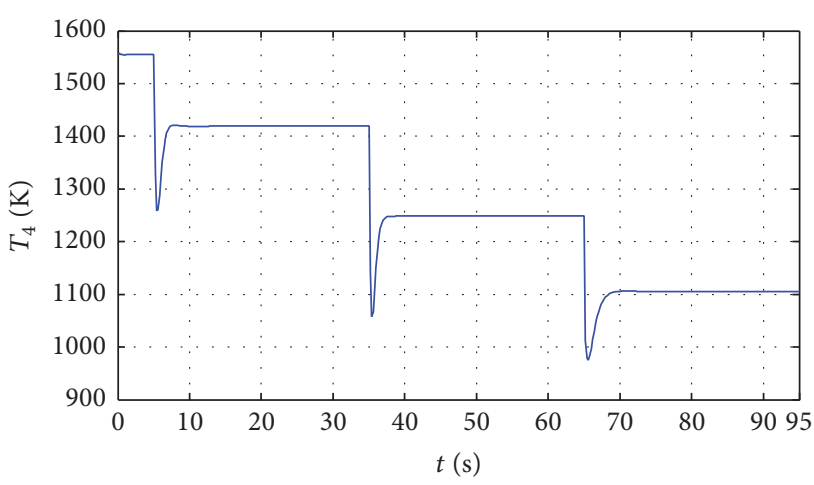

FIGURE 9: Simulation result of temperature of combustor outlet.

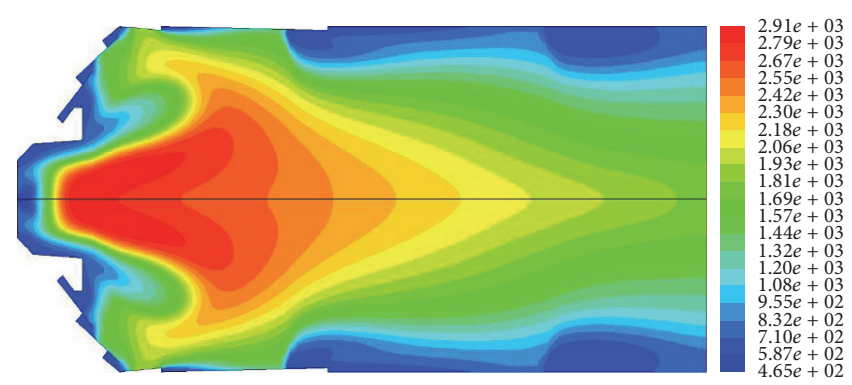

FIGURE 10: Inner temperature distribution of combustor. 


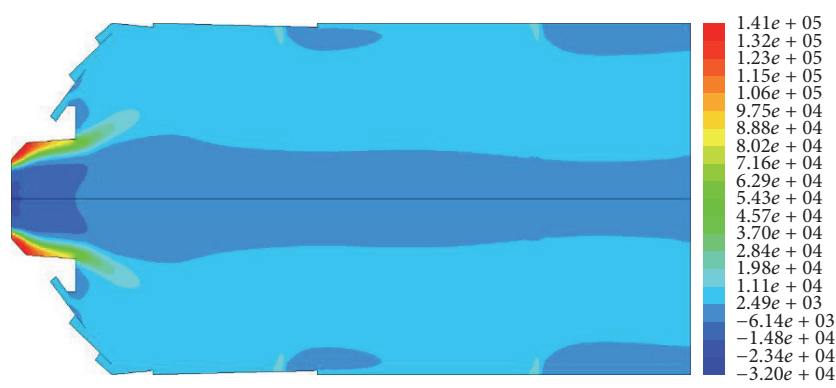

FIGURE 11: Inner total pressure distribution of combustor.

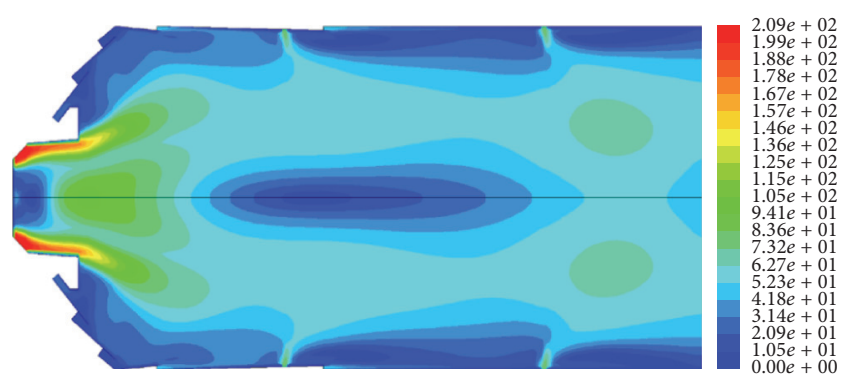

FIGURE 12: Inner velocity distribution of working fluid of combustor.

temperature of outlet section is in the central region of combustor, which is about $1700 \mathrm{~K}$. The cooling effect of combustor wall between the primary holes and head is worse than it is of combustor wall after the primary holes; it can be improved by increasing the air flow through the head.

Figure 11 shows the inner total pressure distribution of combustor; it can be seen that the pressure distribution of main zone is uniform, the combustion process is approximately an isobaric process, and the pressure gradient appears near each hole and on both sides of central recirculation zone. The highest pressure of combustion flow field appears at the swirl holes, and there is low-pressure zone in central recirculation zone, which provides favorable condition for the stable combustion of fuel. The total pressure recovery coefficient of combustor decreases as the load decreases (it is 0.943 and 0.957 on $20 \%$ working condition and $100 \%$ working condition, resp.).

Figure 12 shows the inner velocity distribution of working fluid of combustor; it is clear that there is a central recirculation zone formed by intersection of the swirl generated by swirl holes and the jet-flow generated by primary holes. Meanwhile the central recirculation zone is smaller than the actual one, the reason is as described previously. The maximum velocity of working fluid in combustion flow field appears at the inlet of swirl holes, about $166.5 \mathrm{~m} / \mathrm{s}$, and the average velocity of the working fluid of the combustor outlet is about $42 \mathrm{~m} / \mathrm{s}$.

\section{Conclusion}

Firstly. A new workflow of Simulink/Fluent collaborative running interface is proposed, which provides boundary conditions for Fluent environment by modifying parameters of Journal text directly, instead of tedious UDF programming.
Secondly. The 2D simulation model of combustor is developed in the Fluent environment; the system simulation model which consists of $0 \mathrm{D}$ component simulation models is developed in the Simulink environment; the 2D simulation model of combustor is embedded in the Simulink environment by encapsulating the written collaborative running interface of Simulink/Fluent to S-Function module, to realize the simulation zooming.

Thirdly. The system simulation for the rated working condition as well as variable working condition of triaxial gas turbine of a certain type is achieved. The result on one hand shows that the errors of simulation zooming are less than 5\%; on the other hand, it shows that the Simulink/Fluent collaborative simulation zooming can make the inner working conditions of combustor be observed specifically, based on the overall performance matching analysis; thus an effective technical means for the structural optimization design of combustor is provided.

\section{Nomenclature}

LC: Low-pressure compressor

HC: High-pressure compressor

C: Combustor

HT: High-pressure turbine

LT: Low-pressure turbine

PT: Power turbine

n: $\quad$ Rotor speed

G: Mass flow

$J: \quad$ Inertia of rotor

$\beta$ : Pressure ratio

$\eta$ : Efficiency

$C_{p}$ : Specific heat $[\mathrm{kJ} /(\mathrm{kg} \cdot \mathrm{K})]$

e: Expansion ratio

$T: \quad$ Temperature $[\mathrm{K}]$

$k$ : Adiabatic coefficient

$N$ : Output power [kw]

$L: \quad$ Load power $[\mathrm{kw}]$

$p$ : Pressure $[\mathrm{kPa}]$

R: $\quad$ Gas constant

$h$ : Specific enthalpy $[\mathrm{kJ} / \mathrm{kg}]$.

\section{Competing Interests}

The authors declare that there is no conflict of interests regarding the publication of this paper.

\section{Acknowledgments}

The present work is supported by the Fundamental Research Funds for the Central Universities of China (no. HEUCFZ160306).

\section{References}

[1] H.-B. Xie, D.-B. Zhang, and L.-C. Shen, "Collaborative simulation based on MATLAB/Simulink and FLUENT," Journal of System Simulation, vol. 19, no. 8, pp. 1824-1856, 2007. 
[2] W. Bao, W. P. Li, and T. J. Chang, "Closed-loop control simulation technology of dstributed parameter system based on Fluent/Matlab interface," Journal of System Simulation, vol. 20, no. 11, pp. 2851-2855, 2008.

[3] S. He, Research on Steady-State Optimizing Control System of Scramjet Thrus, Harbin Institute of Technolog, Harbin, China, 2008.

[4] M. Y. He, S. Zhou, and Z. P. Huang, "Simulink/Fluent collaborative simulation for PEM fuel cells," Journal of System Simulation, vol. 23 , no. 1, pp. 38-43, 2011.

[5] S. Q. Tang, C. Q. Huang, and M. Y. Yong, "Fluent/Simulink collaborative simulation for missile separating from cavity," Electronics Optics \& Control, vol. 20, no. 3, pp. 69-73, 2013.

[6] MathWorks Corporation, Matlab Help of Simulink User's Guide, Version R2010a, MathWorks, Natick, Mass, USA, 2010.

[7] Y. Mu, Numerical Investigation on Combustion Flows and Pollutions of Dual-fuel Combustor in Gas Turbine, Harbin Engineering University, Harbin, China, 2010.

[8] W. Q. Tao, Advances in Computational Heat Transfer, Science Press, Beijing, China, 2000.

[9] X. Yuan and Z. Y. Chen, Analysis and Calculation of Fluid Mechanics, Tsinghua University Press, Beijing, China, 2002.

[10] G. D. Swenson, Numerical Simulation of Combustion Instabilities in Gas Turbine Combustors, with Applications, California Institute of Technology, San Diego, Calif, USA, 2000.

[11] Y. S. Zhang and S. A. Orszag, "Two-equation RNG transport modeling of high Reynolds number pipe flow," Journal of Scientific Computing, vol. 13, no. 4, pp. 471-483, 1998.

[12] Z. Q. Zhu, Numerical Simulation of the Combustion Processes and the Pollutant $\mathrm{NO}_{x}$ Emission in a w-Shape Flame Boiler Furnace, North China Electric Power University, Beijing, China, 2001.

[13] J. Warnatz, U. Maas, and R. W. Dibble, Combustion, Springer Press, Berlin, Germany, 2006.

[14] W. P. Jones and J. H. Whitelaw, "Calculation methods for reacting turbulent flows: a review," Combustion and Flame, vol. 48, pp. 1-26, 1982.

[15] M. Yu, J. Lin, and T. Chan, "Numerical simulation of nanoparticle synthesis in diffusion flame reactor," Powder Technology, vol. 181, no. 1, pp. 9-20, 2008.

[16] H. Ounis, G. Ahmadi, and J. B. McLaughlin, "Brownian diffusion of submicrometer particles in the viscous sublayer," Journal of Colloid And Interface Science, vol. 143, no. 1, pp. 266-277, 1991.

[17] S. Jain, Three-Dimensional Simulation of Turbulent Particle Dispersion, University of Utah, Salt Lake City, Utah, USA, 1995.

[18] I. V. Adamovich, J. W. Rich, and G. L. Nelson, "Feasibility study of magnetohydrodynamics acceleration of unseeded and seeded airflows," AIAA Journal, vol. 36, no. 4, pp. 590-597, 1998.

[19] S. M. Camporeale, B. Fortunato, and M. Mastrovito, "A modular code for real time dynamic simulation of gas turbines in simulink," Journal of Engineering for Gas Turbines and Power, vol. 128, no. 3, pp. 506-517, 2006.

[20] W. Ma, Y. Liu, and M. Su, "New scaling method for compressor maps using average infinitesimal stage," Chinese Journal of Mechanical Engineering, vol. 20, no. 6, pp. 24-28, 2007.

[21] R. Yang, Simulation Research of CRGT Cycle and Water System, Harbin Engineering University, Harbin, China, 2010. 

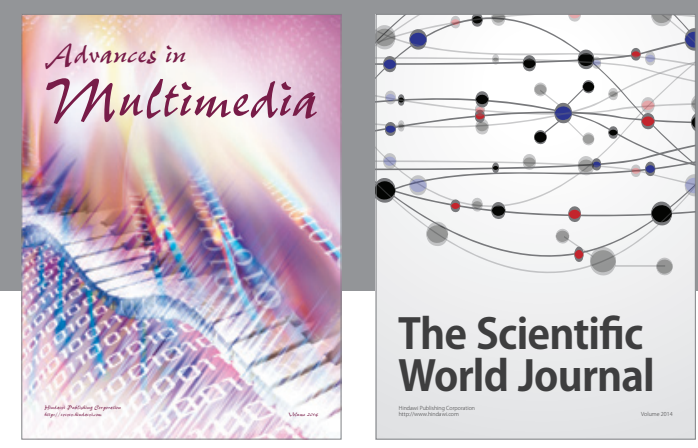

The Scientific World Journal
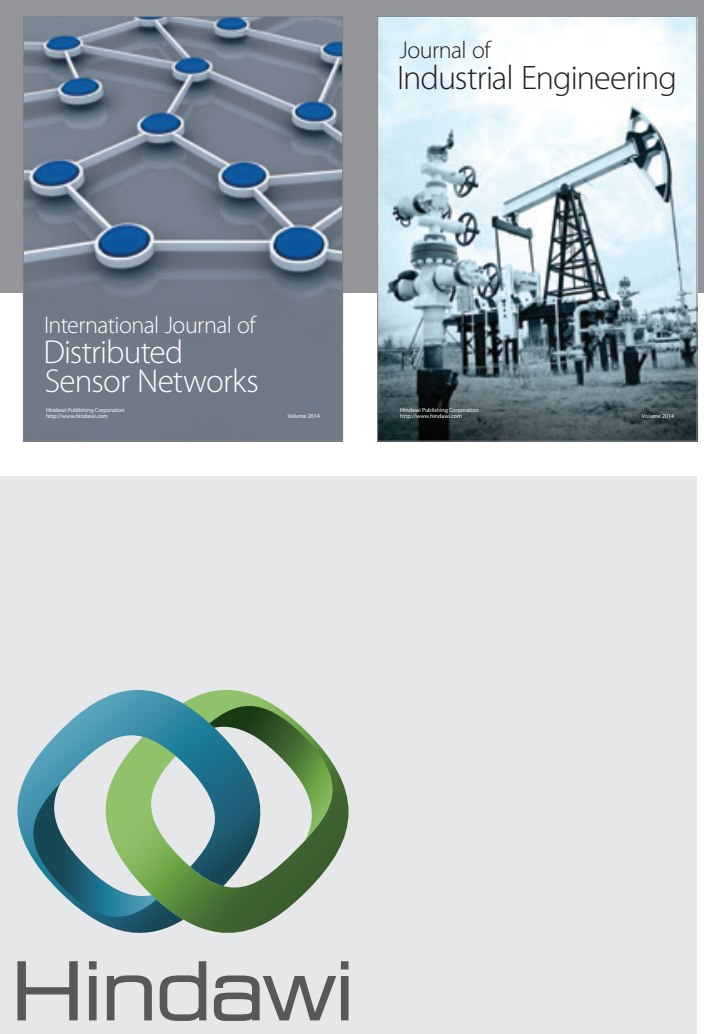

Submit your manuscripts at

https://www.hindawi.com

\section{Computer Networks} and Communications
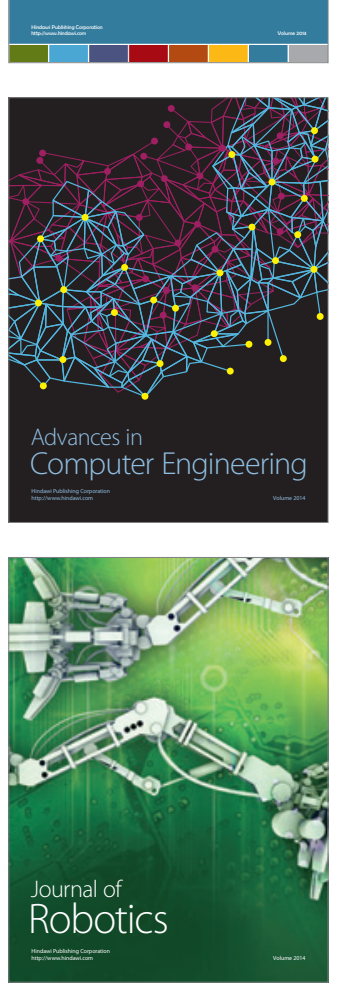
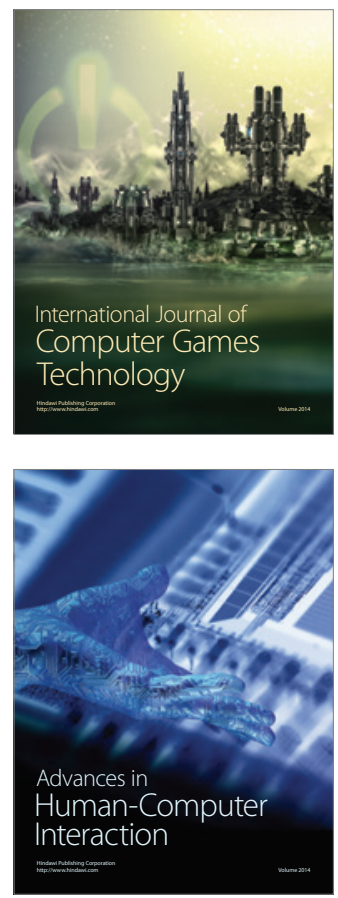
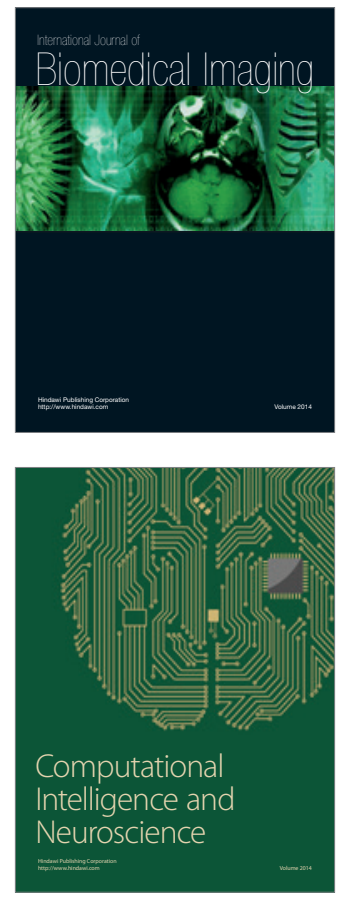
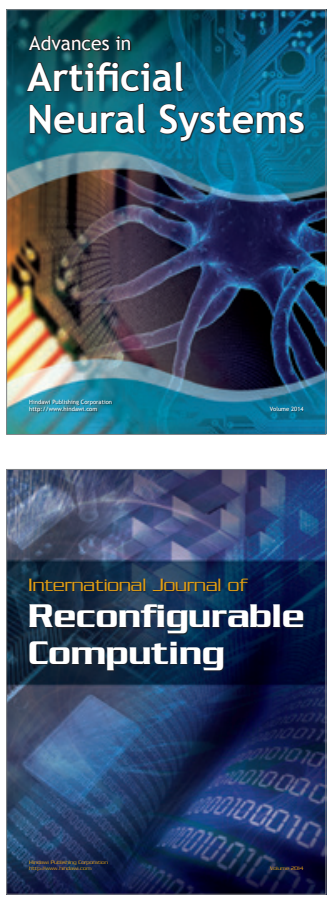
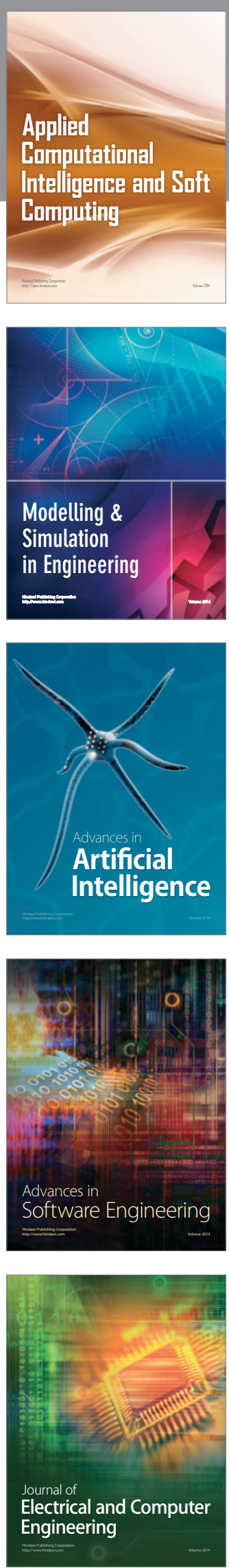